\title{
Lexis
}

Journal in English Lexicology

15 | 2020

The adjective category in English

\section{Composite colour strings in English: adjectival or nominal?}

\section{Philippe De Brabanter and Saghie Sharifzadeh}

\section{(2) OpenEdition}

Journals

\section{Electronic version}

URL: http://journals.openedition.org/lexis/4366

DOI: $10.4000 /$ lexis.4366

ISSN: 1951-6215

\section{Publisher}

Université Jean Moulin - Lyon 3

\section{Electronic reference}

Philippe De Brabanter and Saghie Sharifzadeh, «Composite colour strings in English: adjectival or nominal? », Lexis [Online], 15 | 2020, Online since 13 June 2020, connection on 17 December 2020 URL : http://journals.openedition.org/lexis/4366 ; DOI : https://doi.org/10.4000/lexis.4366

This text was automatically generated on 17 December 2020 .

\section{(c) (i) (9)}

Lexis is licensed under a Creative Commons Attribution-NonCommercial-NoDerivatives 4.0 International License. 


\title{
Composite colour strings in English: adjectival or nominal?
}

\author{
Philippe De Brabanter and Saghie Sharifzadeh
}

We would like to thank the three reviewers, whose comments have very much motivated us to improve the structure and readability of the present paper.

\section{Introduction}

1 It is uncontroversial that an English colour term (henceforth often CT) exists in the lexicon either as an adjective (1)-(2) or as a noun (3). Most dictionaries have separate sub-entries for each category: 1

(1) She was running, running towards the green door. $(\mathrm{BNC})^{2}$

(2) His teeth look green. (BNC)

(3) In England green is supposed to be an unlucky colour. (BNC)

Examples (1) and (2) allow us to distinguish between the two main functions that a colour adjective can fulfil. In (1), green is the head of an adjective phrase that modifies the noun that follows. One traditionally talks of the 'attributive' function of adjectives in this respect. In (2), green occurs as head of the adjective phrase that functions as predicative complement of look. In this role, one traditionally talks of the 'predicative' function. We adopt those terms on the understanding that it is really adjective phrases that are used attributively and predicatively. Example (3) has the noun green occurring as the head of the subject NP green. In the dictionaries we consulted, almost all the examples provided for colour words as nouns have them as complements of a preposition (in white), head of an NP that includes a PP-complement of the colour word (the black of the night sky), or head of an NP with a plural inflection (vibrant blues and yellows). These unambiguously nominal occurrences do not share a common type of function that could be captured by a single label. That is why we will use the label 'other' to stand for the functions that the lexicographical literature has associated with colour nouns. That label will contrast with the labels 'attributive' and 'predicative'. ${ }^{3}$ 
When looking at colour words occurring alone as in (1) to (3) - namely without modification, complementation or determination - there appear to be no reasons to challenge the simple classification outlined above. However, as soon as one allows for more complex structure around a colour word, the picture changes. The starting point of the present research was the realisation that when (what most dictionaries and grammar books regard as) a colour adjective used predicatively is modified by a word like dark, this putative adjective may 'turn' into a noun:

(4) [...] until the broccoli has turned a dark green with no hint of blue. (COCA)

The occurrence of the indefinite article as determiner of dark green shows that dark green is a nominal, ${ }^{4}$ hence that its head green is a noun. Still, we thought, this substitution of a noun for (what is assumed to be) an adjective is not obligatory, since we introspectively judged that dark green could occur without the indefinite article, as in (4'). This judgment was confirmed by corpus data such as (5):

(4') [...] until the broccoli has turned dark green with no hint of blue. [modified]

(5) Here, in the cafeteria, the carpet turned dark green, [...] (COCA)

The main lesson to be drawn from an example like (4) is that a colour noun can occur in at least one environment that is not subsumed under the 'other' heading, namely as head of a predicative complement, a position normally thought to be the prerogative of adjectival CTs.

In this paper, we look into the category membership of CTs as adjectives vs. nouns, by focusing on their occurrence in composite colour strings. ${ }^{5}$ In particular, we challenge the assumption that attributive and predicative CTs are indisputably adjectival, and look into the possibility that more occurrences of CTs than have been allowed for so far may have to be categorised as nominal. Section 1 is a review of the relevant literature. We conclude that the most popular view - composite CSs are adjective-adjective compounds - is not without its problems, but nor are competing hypotheses. Section 2 reports on the corpus study we carried out on the assumption that it would confirm or disconfirm our initial intuitions, and would provide us with useful additional insights. Section 3 is devoted to a detailed discussion of two of the main results to emerge from the corpus study. Section 4 makes a cautious proposal for categorising CTs. This is followed by our conclusion.

\section{Literature review}

There is widespread agreement that composite CSs like dark green, brown-grey or bluishgrey, as occur in attributive and predicative positions, are adjectival compounds (Jespersen [1942, VI: 165]; Attal [1987: 126]; Bauer \& Huddleston [2002: 1658]; Plag [2003:143]; Aarts [2007:134]; Conti [2007:134]). The few dissenting voices are addressed below. Writers who classify dark(-)green ${ }^{6}$ as an adjectival compound also tend to concur that both bases in the compound are themselves adjectives. ${ }^{7}$ Besides, they also agree that dark(-)green conforms with the majority of compounds in instantiating a modifier-head relation. In other words, in examples like dark(-)green, the standard assumption is that an adjective modifies an adjective. 
5 This pattern of modification is clearly unusual, and may prompt four main responses. First, one may bite the bullet and accept, without further ado, that adjectives can modify adjectives, which is what most of the linguists mentioned above do. Second, one may argue precisely from this oddity to strengthen the view that dark(-)green must be an adjective-adjective compound (as opposed to a syntactic phrase). Third, one may accept that dark(-)green is an adjectival compound while rejecting the analysis of dark as an adjective. Finally, one may question the category of the CT: is it (always) an adjective? This last response may go together with complete or partial acceptance or with rejection of the compound analysis.

6 Since the first response does not engage with the issue and is therefore uninteresting from a theoretical point of view, we turn at once to the second response, advocated most explicitly by Marchand, who has a subcategory of compounds that are "determined by first-words which syntactically could not be their modifiers" [1966: 15]. To this category belong easy-going and icy-cold but also dark-blue, dark brown, light blue, light green, bluish-gray, etc. ([1966: 48-49]; Marchand's hyphenation). Marchand argues that these combinations must be compounds; in ordinary phrases, no adjective could be modified by another adjective.

7 Working within a generative semantics framework, Meys [1975: 173-178] adopts the third response. He argues that "apparent [ADJ + ADJ] compound adjectives" [1975: 174] have an underlying semantic structure which in most cases actually displays modification of the second element by the first "in an adverbial way" [1975: 173]. This includes examples which have a CT as their second element (though none of the examples given by Meys have a modifier like bright, dark, light or pale as their first element). ${ }^{8}$ Two underlying semantic structures are distinguished. In cases like redbrown, Meys suggests, the meaning is something like 'brown in a red way' (this gloss is merely intended as a way of capturing a meaning). Why, then, is this meaning lexicalised as red-brown? Because, says Meys, other options - in a red way or redly - are out. Presumably, Meys would adopt a similar reasoning for dark(-)green: a dark(-)green door is 'green in a dark way'. For cases like bluish-green Meys proposes 'green like blue' as the underlying semantics. Again, as such a form would not lend itself to lexicalisation, another word-formation process must be resorted to, yielding bluishgreen. Meys's conclusion is that it can be argued "that what look like [ADJ + ADJ] compound adjectives are in reality [ADV + ADJ] compounds in which the ending has been 'suppressed' in some way or another. For colour-adverbs' this seems in fact obligatory" [1975: 176].

Although not directly addressing the dark(-)green examples, Adams also argues that first elements of compound adjectives like right-thinking or slow-moving are not adjectives but adverbs without their suffix [Adams 1973: 93-94; 2001: 90]. It must be noticed, however, that the 'unmarked adverbs' in her examples can either (i) be used as adverbs in other structures in which they modify a verb (they think right) or (ii) be replaced by their -ly counterparts in the adjectival compounds (slowly moving). Neither of these properties is exhibited by dark(-)green, which suggests that first elements like dark make for less convincing adverbs.

9 All the authors mentioned so far take it for granted that the CT in attributive or predicative composite CSs is an adjective. Some, however, have raised the question of 
the category membership of the CT (our fourth possible response above). Poutsma distinguishes three cases:

i. of a dark green [cf. Eyes of a pale blue that might have tended toward coolness... (COCA)]: here the colour word is only partially converted to a noun, because "such a noun as colour or shade is readily supplied" [1914: 380] - case (i) would fall under our 'other' category;

ii. a dark green not preceded by of [e.g. The fields are a fresh dark green]: total conversion to noun - case (ii) is interesting because it falls under our predicative category;

iii. dark green not preceded by of $a$ [e.g. the leaves are dark green]: here, "the adjective [...] is preceded by an adverbial modifier" [1914: 380].

In other words, when a composite CS is not preceded by a determiner, the CT is an adjective, albeit one modified by an adverb (cf. Meys, and possibly Adams). When a composite CS is preceded by a determiner, the CT is partially (in (i)) or totally (in (ii)) a noun.

More radical are the views defended by McCawley, according to whom CTs have dual category membership, being both adjectives and nouns at the same time. This, McCawley argues, is rendered necessary by the existence of examples like (6), in which blue must be a noun - as it is modified by the adjective deep - but also an adjective - as it modifies the noun shirt.

(6) a deep blue shirt [1988: 44]

Against the idea that deep might be an adverb in (6), McCawley [1988] adduces the existence of -ly forms, which are excluded in contexts like (6), as shown by (7)-(8), McCawley's examples:

(7) Ted's necktie was deep/*deeply blue.

(8) The curtains were light/*lightly green..$^{10}$

Aarts [2007: 134] argues against this "undesirable dual categorization of colour terms", ${ }^{11}$ and claims that it can be avoided if one adopts the adjective-adjective compound analysis in both attributive and predicative positions:

(9) a $[$ deep blue] shirt

(10) the shirt is $\left[_{A}\right.$ deep blue] (Aarts's examples)

Aarts's proposed solution takes us back to square one, so it is time to take stock. Most writers take on board the idea that composite CSs in the attributive and predicative positions are adjective-adjective compounds, but without explaining how an adjective can modify an adjective. Marchand takes this very oddity as evidence that we are dealing with compounds, not phrases. Others, we have seen, think it a problem (Meys, Adams, McCawley). Pullum \& Huddleston go so far as to claim that, whereas nouns "characteristically take adjectives as pre-modifiers" [2002: 536], adjectives "cannot be modified by (other) adjectives" [Pullum \& Huddleston 2020: 528]. The same authors, however, working in tandem with Payne (Payne et al. [2010: 52-55]), have now rejected that ban and argue for the adjective-adjective analysis, albeit without considering dark(-)green a compound (just an established collocation).

This complex situation offers very little hope of being disentangled if we stay focused on examples of the dark(-)green type. But we thought that another angle was possible. It seemed to us, introspectively, that composite CSs could be inflected for grade, and that the comparative and superlative inflections would be carried by the first, leftward, element in the string (darker(-)green and darkest(-)green). The dominant assumption in 
the word-formation literature, however, is that inflectional mechanisms should apply only to the output of word-formation processes (e.g. Quirk et al. [1985: 1548]). On this picture, compounding of dark and green would take place first, yielding dark(-)green, and only then would comparative and superlative inflections be added to that output, yielding dark(-)greener and dark(-)greenest.

14 Since, however, we assumed the latter forms to be less likely to turn up than darker(-)green and darkest(-)green, we found a further motivation to question the sort of univocal treatment that CTs in attributive and predicative positions were given in most of the literature. In particular, it was worth considering the extent to which the CTs of composite CSs occurred as nouns - a possibility which, as we have seen, was already pointed out by Poutsma in predicative use, but also acknowledged in passing by Aarts [2007: 134] and by Payne et al. [2010: 54]. Our reasoning was that, if green in dark(-)green was a noun, then it would be natural to regard dark as an adjective, and unsurprising for dark to be marked for grade. This, we thought, provided an elegant account of what we assumed to be the data.

Still, we needed to get clearer about the validity of our introspective judgments, so as to be in a better position to assess the various views in the literature and our own as well. That is why we conducted a corpus study, the details of which are set out in the next section.

\section{Corpus study}

16 This section describes our corpus study. We spend some time on problems encountered in the collection of the relevant data. It is good to be explicit about the decisions we made, since they are likely to have an impact on the descriptions supplied and the conclusions we eventually draw from them.

\subsection{Materials}

Using the online interface available at https://www.english-corpora.org, we searched two corpora, the British National Corpus (BNC, Davies [2004-]) and the Corpus of Contemporary American English (COCA, Davies [2008-]) in order to obtain data for strings containing a CT. The corpus data were collected mainly in 2011 and 2012, at a time when the COCA contained about 450 million words. The number of words in the BNC, about 100 million, has remained (and will remain) unchanged.

18 We needed our queries to give us information on composite CSs, with a view to determining whether and to what extent they surfaced in a nominal capacity outside of the customary syntactic contexts that we labelled as 'other'. To this end, we built queries made up of two elements. The second one was always a CT from among the 11 'basic colour terms' that anthropological linguists have identified cross-linguistically (Berlin \& Kay [1969: chapter 1]; Kay \& McDaniel [1978]): primary ones, namely black, white, blue, green, red, yellow; non-primary ones, namely brown, grey, orange, pink, purple. For one of those, we allowed for two spellings, grey and gray. These 12 CTs we combined with a first element from among four adjectives singled out by Bauer \& Huddleston [2002: 1658] as "occur[ring] productively with colour terms": bright, dark, light, pale. 
(i)

(ii)

(iii)

brightest/darkest/lightest/palest black/blue/brown/green/grey/gray/orange/pink/purple/ red/white/yellow

bright/dark/light/pale black/blue/brown/green/grey/gray/orange/pink/purple/red/white/ yellow

brighter/darker/lighter/paler black/blue/brown/green/grey/gray/orange/pink/purple/ red/white/yellow
We took great care to 'clean up' the data so as to be left only with directly relevant material. As a general rule, we relied on a semantic criterion: the CT must occur in something close to its literal sense, i.e. denote exclusively a colour, a dye, a patch of colour. Other uses were discarded. It was mainly putative nominal occurrences that were affected. For example, metonymic uses of CTs were eliminated, as in (11), (12) and (13), where the NP refers to a rowing crew, a kind of wine, and an ethnic group, respectively. In contrast, attributive and predicative uses are less affected, as they tend to keep denoting a colour, even in cases where the overtly nominal counterpart would be discarded. Thus, we retained (14) and (15) in contrast to (12) and (13), even though the semantics of dark red wine and white people may not be fully compositional (e.g. light black students aren't exactly students that are (a) light black). But some of those uses come up for removal all the same: (16), though it has green modified by lighter, was deemed not relevant because green denotes a political orientation on top of a colour - a decision that affects the results for query (ii). We are well aware that some of our choices may raise issues, but choices are inevitable.

(11) [...] the 1992 University Boat Race. On paper it appears the light blues are inches shorter... and a few months older... but what about on the water? (BNC) [discarded]

(12) One solution is to drink only paler reds from Northern Europe - the Loire or Burgundy - rather than darker, southern wines. (BNC) [discarded]

(13) Immersed in a racist society that valued White skin, lighter Blacks with straight hair were afforded more access than other Blacks. (COCA) [discarded]

(14) The cork of the bottle popped free of its own accord and then dark red wine appeared in the glass. (COCA) [retained] 
(15) These include the competition dances, the studied contrast in the juxtaposed scenes of the light black students versus the dark black students. ${ }^{13}$ (COCA) [retained]

(16) Observers blamed the poor showing on the fact that the major parties had taken on board many of the "lighter green" policies of Die Grünen. (BNC) [discarded]

Regarding query (i), most of the hits dismissed as spurious had light meaning 'not too sweet or strong' (e.g. light red wine) or 'not heavy or thick' (e.g. light blue jeans). Regarding (ii) and (iii), with, respectively, comparative and superlative forms of the four adjectives used in combination with the CTs, hardly any cleaning up was necessary, except for a few occurrences of brightest black $+\mathrm{N}$ in the COCA, with brightest in the sense of 'most intelligent'.

\subsubsection{Hyphenated strings}

Here we had to devise a large number of separate queries corresponding to (i) to (iii) in Table 1. For the sake of exemplification, consider the hyphenated counterpart to (i). The query syntax of our online interface provides no way of requesting bright/dark/ light/pale followed by a hyphen followed by one of the 12 basic colour terms. As a result, we had to run 24 queries on the following pattern: ${ }_{-}^{-C T, 12}$ with a plain and 12 with a plural CT. These queries returned all the hyphenated strings whose second element is a colour word. We then had to select those whose first element was any of bright/dark/ light/pale. This procedure we repeated for each colour term. Since we did this with uninflected first elements (i), with their comparative forms (ii), and superlative forms (iii), we ended up with $144{ }^{14}$ potential sets of concordance lines corresponding to (i)(iii). As it turned out, very few queries with comparative and superlative forms yielded any hits at all (see Table 3), and only 2 of these hits were spurious.

\subsection{Quantitative data}

Table 2 gives cleaned up figures for the unhyphenated strings, distinguishing between plain CTs and plural CTs (abbreviated as plur.). ${ }^{15}$ Table 3 gives the corresponding figures for hyphenated strings.

Table 2: frequencies of unhyphenated occurrences in the BNC and COCA

\begin{tabular}{|l|l|l|l|l|l|l|}
\hline \multicolumn{2}{|c|}{} & \multicolumn{2}{l|}{ BNC } & \multicolumn{2}{l|}{ COCA } & \multirow{2}{*}{ TOTAL } \\
\cline { 3 - 6 } & Unhyphenated occurrence & plain & plur. & plain & plur. & \\
\hline (i) & bright etc. + CT & 2599 & 32 & 12963 & 216 & $\mathbf{1 5 8 1 0}$ \\
\hline (ii) & brighter etc. + CT & 65 & 4 & 242 & 23 & 334 \\
\hline (iii) & brightest etc. + CT & 26 & 2 & 72 & 10 & $\mathbf{1 1 0}$ \\
\hline
\end{tabular}

As regards query (i), the BNC and the COCA returned large numbers of hits for plain forms. We examined separate random samples of 500 occurrences for each. The figures 
obtained from the 500-samples were extrapolated to the whole set of results. For example, the 500 BNC sample for bright etc. + CT yielded 491 relevant hits. That figure was multiplied by $5.294(=2647 / 500)$ to obtain an estimate of the total number of relevant hits for bright etc. + CT in the entire BNC: $491 \times 5.294=2599$. Note that the number of relevant hits is greater than that of the hits we were able to assign to our three functional classes, because, though clearly relevant, some hits could not be classified beyond reasonable doubt, and were therefore labelled as 'undecidable' (this is not shown in our tables). That is why the totals in Tables 4 and 6 sometimes fall short of the numbers in Table 2.

For the part of query (i) that concerned plural forms, and for queries (ii) and (iii), all of which yielded manageable numbers of hits, the results were looked through exhaustively, each occurrence being examined separately.

Table 2 is pretty much self-explanatory and contains few surprises. Noteworthy is the fact that the number of plural occurrences, which are unambiguously nominal, is much lower than that of plain ones. Keep in mind, however, that plain forms are in principle capable of occurring either as adjectives or as nouns. In Section 2.2.1., we look at the distribution of plain and plural forms over the three functions we distinguished.

Turning now to the hyphenated strings, it must be pointed out that five sets of results contained in excess of 100 hits in the COCA. For each of these (blue, brown, green, red, yellow), we examined a random sample of 100 occurrences, and extrapolated the results thus obtained using the same method as above.

Table 3: frequencies of hyphenated occurrences in the BNC and COCA after data clean-up

\begin{tabular}{|l|l|l|l|l|l|}
\hline \multicolumn{2}{|c|}{ Hyphenated occurrences } & BNC plain & BNC plur. & COCA plain & CocA plur. \\
\hline (i) & bright- etc. + CT & 202 & 0 & 1653 & 0 \\
\hline (ii) & brighter- etc. + CT & 1 & 0 & 3 & 0 \\
\hline (iii) & brightest- etc. + CT & 0 & 0 & 1 & 0 \\
\hline
\end{tabular}

It is immediately apparent that the corpus contains far fewer hyphenated than unhyphenated composite CSs. The disparity between queries (ii) and (iii) and query (i) is even more striking here than in the case of the unhyphenated strings. (17) and (18) are rare examples of results for queries of type (ii) and (iii), respectively.

(17) Turn the heat to medium low. Wait till the whites coagulate and the yolks show darker-yellow, frecklelike spots. (COCA)

(18) Even the bench at the foot of the bed wears a charmingly distressed coat of palest-pink paint. (COCA)

In Section 3.2., we consider possible reasons why there are so few hyphenated composite CTs whose first element is inflected.

Another striking, if not unexpected, finding is that the corpora contain no relevant occurrences of plural forms of the hyphenated strings. The few there were before clean-up were discarded because they did not denote colours but people, e.g. a sports team (the Cambridge light-blues vs. the Oxford dark-blues). 


\subsubsection{Functional distribution}

29 We now turn to the distribution of the various composite CSs, hyphenated or not, across the three main functions distinguished for the purposes of this study: attributive, predicative, other. For the sake of completeness, we first need to say a few more words on the predicative category. We decided to also assign to it those few examples in which a composite CS occurred in a postpositive (19) or supplementary (20) position. This we did because these two 'minor' functions are much more similar to the predicative than the attributive function, witness the fact that reputedly 'predicativeonly' adjectives like afraid can also occur in a postpositive or supplementary capacity, while 'attributive-only' adjectives like main cannot, cf. (21): ${ }^{16}$

(19) I see jowls sagging, eyebrows high on trembling foreheads, cheeks bright-white. (COCA)

(20) Smoke poured upwards, pale-grey and blurred, like make-up smudged by tears. (BNC)

(21) a. a patient afraid to die

b. Afraid to make noise, I sat on the bed.

c. *one of the roles main for machine learning

d. *Main amongst the characters, Holden [...]

(22) [(i), attributive] I wanted to wear really bright red lipstick too, just for the sheer hell of it! (BNC)

(23) [(ii), predicative] Now the patch she had stirred was darker grey. (BNC)

(24) [(iii), other] After moving across from the lightest yellow to the deepest reds and darkest grays, I end up with a double row of paint. (COCA)

Another (expected) finding is that there are major distributional differences between plain and plural colour strings, with the latter falling almost entirely under 'other' (see (24) above). Remarkable are the four exceptions to this pattern, three of them with resultative predicative complements, as in the following example:

(25) [...] the raven was Life Creator and carefully painted the other birds bright greens and blues, and was left with only black for himself. (COCA)

In either analysis of bright greens and blues - bright modifies greens, or it modifies the coordination greens and blues - greens occurs in a predicative capacity.

Table 4: Distribution of the unhyphenated strings across the three functions (BNC and COCA together)

\begin{tabular}{|c|c|c|c|c|c|c|c|c|}
\hline & & \multicolumn{2}{|c|}{ attributive } & \multicolumn{2}{|c|}{ predicative } & \multicolumn{2}{|l|}{ other } & \multirow{2}{*}{ TOTAL } \\
\hline & & plain & plur. & plain & plur. & plain & plur. & \\
\hline (i) & bright etc. $+\mathrm{CT}$ & 10462 & 0 & 3107 & 4 & 1811 & 243 & 15627 \\
\hline (ii) & brighter etc. $+\mathrm{CT}$ & 105 & 0 & 118 & 0 & 83 & 27 & 333 \\
\hline
\end{tabular}




\begin{tabular}{|l|l|l|l|l|l|l|l|l|}
\hline (iii) & brightest etc. + CT & 28 & 0 & 13 & 0 & 53 & 12 & 106 \\
\hline
\end{tabular}

The totals in Table 4 do not add up exactly to the figures for cleaned up data reported in Table 2. As explained above, that is because a small proportion of examples were ambiguous and could not therefore be assigned with certainty to one of the three functions. By way of illustration, in (26), there is hesitation between 'other' and attributive: one might assume that there is ellipsis of colour after darkest brown and almost-gold, just as there is ellipsis of symptoms in (27):

(26) [...] they had seemed almost to change colour from darkest brown to angry almost-gold. (BNC)

(27) Symptoms occur at any age and range from mild to severe. (COCA)

If it is assumed that darkest brown in (26) is the surface realisation of an underlying $\left[_{\mathrm{NP}}\right.$ [AP $_{\mathrm{AP}}$ darkest brown] $\left[{ }_{\mathrm{N}}\right.$ colour]] structure, then darkest brown occurs attributively. Because of the existence of this alternative analysis, we decided not to include this example in the results reported in Table 4.

Another aspect worth emphasising is that only in the 'other' function do plural (hence unambiguously nominal) forms make up a sizeable proportion of the hits. Aside from the very few exceptions mentioned above, they do not occur in the attributive and predicative functions. Does that mean that plain CTs are all adjectives, making almost all attributive and predicative uses adjectival? That would be a hasty conclusion. We look at another nominal marker in Table 7.

Let us now turn to the hyphenated strings. Table 5 displays their distribution across the three functions. No columns are provided for plural forms, for which there were no hits (see Table 3). Moreover, the striking scarcity of hits for queries (ii) and (iii) may reflect a constraint against internal inflections, which in turn may suggest that hyphenated strings are more compound-like than unhyphenated ones.

Table 5: Distribution of the hyphenated strings across the three functions (BNC and COCA together)

\begin{tabular}{|l|l|l|l|l|}
\hline & & attributive & predicative & other \\
\hline (i) & bright- etc. + CT & 1790 & 53 & 12 \\
\hline (ii) & brighter- etc. + CT & 3 & 0 & 1 \\
\hline (iii) & brightest- etc. + CT & 1 & 0 & 0 \\
\hline
\end{tabular}

Examples (17) and (18) (repeated below) offer good illustrations of attributive examples for queries of types (ii) and (iii), while (28) illustrates a type-(i) case that falls under 'other':

(17) Turn the heat to medium low. Wait till the whites coagulate and the yolks show darker-yellow, frecklelike spots. (COCA)

(18) Even the bench at the foot of the bed wears a charmingly distressed coat of palest-pink paint. (COCA) 
(28) [...] the compounds are really quite beautiful, occurring in shades of bright-red, yellow, and brown. (COCA)

Table 5 shows that, once again, the attributive function predominates, but this time overwhelmingly. The proportion of hyphenated hits in the predicative and other functions is strikingly low indeed. Table 6 brings out the differences in the functional distribution of unhyphenated and hyphenated strings, providing percentages for easier comparison.

Table 6: Comparison of the functional distribution of hyphenated and unhyphenated strings, in percentage points (BNC and COCA together)

\begin{tabular}{|l|l|l|l|l|l|l|l|}
\hline & \multicolumn{3}{|c|}{ attributive } & \multicolumn{2}{l|}{ predicative } & \multicolumn{2}{l|}{ other } \\
\hline & & - hyphen & + hyphen & - hyphen & + hyphen & - hyphen & + hyphen \\
\hline (i) & bright etc. + CT & 66.9 & 96.5 & 19.9 & 2.9 & 13.1 & 0.6 \\
\hline (ii) & brighter etc. + CT & 31.5 & 75 & 35.4 & 0 & 33 & 25 \\
\hline (iii) & brightest etc. + CT & 26.4 & 100 & 12.3 & 0 & 61.3 & 0 \\
\hline
\end{tabular}

The table is mainly informative with respect to query (i). The numbers of hyphenated hits for queries (ii) and (iii) are so low as to prevent robust comparison. But the figures for (i) are interesting. They show clearly that hyphenated colour strings are much less hospitable than the unhyphenated ones to predicative and other uses, i.e. those in which nominal CTs can occur or necessarily occur, respectively. This raises the possibility that hyphenated strings behave more definitely like adjectives than their unhyphenated counterparts.

The last tables we will look at (Tables 7 and 8) focus on the predicative position. We have seen that some predicative CTs are unambiguously nominal. Next to (rare) plurals, another reliable indicator of nominal character is the presence of a determiner. Remarkably, Table 7 shows that in none of the three queries are the proportions of hits with a determiner negligible. For (ii), they are very high indeed since examples like (29) are almost twice as frequent as those without a determiner, as in (30). The numbers of hits for query (iii), exemplified in (31) and (32), are too low to warrant robust observations.

(29) His hair was a lighter blue than his skin - but still blue. (BNC)

(30) Its upper parts are a greyish-blue, turning paler blue lower down to whitish on the belly. (BNC)

(31) Her figure was squat and her skin the palest white, almost glossy like the belly of a fish. (COCA)

(32) So I grow the April-flowering Fritillaria pallidiflora this way. Its bells are palest green. (COCA)

Table 7: Distribution of the unhyphenated strings in predicative position according to whether they take a determiner (BNC and COCA together)

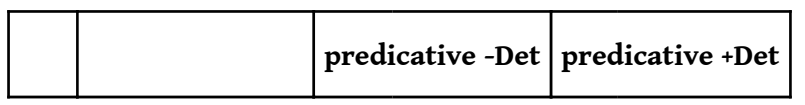




\begin{tabular}{|l|l|l|l|l|l|}
\hline (i) & bright etc. + CT & 2797 & $90 \%$ & 310 & $10 \%$ \\
\hline (ii) & brighter etc. + CT & 43 & $36.4 \%$ & 75 & $63.6 \%$ \\
\hline (iii) & brightest etc. + CT & 9 & $69.2 \%$ & 4 & $30.8 \%$ \\
\hline
\end{tabular}

Table 8: Distribution of the hyphenated strings in predicative position according to whether they take a determiner (BNC and COCA together)

\begin{tabular}{|l|l|l|l|l|l|}
\hline & & \multicolumn{2}{|c|}{ predicative -Det } & \multicolumn{2}{l|}{ predicative +Det } \\
\hline (i) & bright- etc. + CT & 47.4 & $88.6 \%$ & 6.1 & $11.4 \%$ \\
\hline
\end{tabular}

Table 8 only shows the results for query (i) - queries (ii) and (iii) yielded no predicative hits at all (cf. Table 5). Since the proportion of occurrences with a determiner for query (i) is not strikingly different from the one observed for unhyphenated strings, no particular conclusions are warranted.

\section{Discussion}

Besides the quantitative results just reviewed, what theoretical insights can be drawn from the data? Two, especially, will deserve our attention. First is the significance of the composite CSs whose first element is a comparative or superlative form of bright, dark, light, or pale. Second are the differences that surfaced between unhyphenated and hyphenated composite CSs.

\subsection{Accounting for comparative and superlative marking in composite CSs}

In this section, the focus will be almost exclusively on unhyphenated examples, as there are way far too few hyphenated comparative and superlative occurrences in the BNC and COCA (cf. Table 5).

The data produced by queries (ii) and (iii) are useful, as they support our initial intuition that composite CSs can be inflected for grade. The commonness of examples like (23), (26), or (29)-(32) questions the viability of two attempts to explain away the oddity of an adjective modifying another adjective, which results from the popular view that dark(-)green is an adjective-adjective compound (cf. Section 1).

\subsubsection{Oddity as an argument in favour of the compound analysis}

Remember that Marchand claimed that this oddity actually strengthened the case for compoundhood: an adjective could not modify another adjective in an ordinary syntactic phrase. The problem now is that the existence of darker(-)green and darkest(-)green suggests that compounds can be inflected internally. As was noted at the end of Section 1, there is a consensus that word-formation processes take place prior to inflectional ones. This is consistent with the view that compounds function in all respects like single words. It could be said that, even though they have a peculiar 
internal structure, they function externally just like single words. Otherwise, they would not be relevantly different from syntactic phrases. Consequently, because "canonical inflection is expressed at the periphery of words" (Haspelmath \& Sims [2010: 95]), this creates a very strong expectation that any inflections a compound might carry would be marked externally.

41 Still, we need to tread carefully here. Several authors (e.g. Anderson [1992]; Bauer [2006]; Blevins [2006]; Lieber [2009]) have noted that compounds may display internal inflection. The question is whether darker(-)green and darkest(-)green fit in any of the categories identified by those authors. In the rest of this section, we examine these categories in turn and show that darker(-)green and darkest(-)green are relevantly different from each one of them.

A first category of examples adduced to illustrate the existence of internal inflections is nominal compounds like wolf's bane (a plant) or human rights commission. These contain a genitive and a plural inflection, respectively. Still, these examples are quite different from darker(-)green and darkest(-)green in that they are not the genitive form of *wolf bane or plural form of *human right commission, which simply do not exist. They are compounds one of whose elements was already inflected before it entered into composition.

But there also exist genuinely inflected forms of compounds. Anderson [1992: 295] adduces the plurals sons in law, men of war, passers-by. Unlike human rights commission and its likes, these have genuine singular counterparts: you can have one son-in-law or many sons-in-law; you can wave at a passer-by or several passers-by, etc. ${ }^{18}$ Still, once again, these examples are relevantly different from darker(-)green and darkest(-)green in that the internal inflection in them is carried by the head of the compound, not by the assumed modifier.

One could think of enlisting another range of examples, involving adjectives like largesized and dark-eyed or small-scale and long-distance. These do indeed have comparative and superlative forms marked internally, e.g. larger-sized or smallest-scale. The analogy, however, fails again. First, though some have classified words like large-sized or darkeyed as adjectival compounds (Kruisinga [1932, II,3: 47]; Bauer [1983: 210]), there is a broad consensus nowadays that they are obtained derivationally from a phrase to which a denominal suffix -ed is added (Jespersen [1942, VI: 428f]; Marchand [1966: 12-13, 208-209]; Meys [1975: 153-154]; Quirk et al. [1985: 414, 1344, 1553]; Bauer \& Huddleston [2002: 1709]; Plag [2003: 95, 153]; Chuquet \& Paillard [2007: 13, fn. 1]). Just as soft-edged is derived from the nominal soft edge by adding the derivational suffix -ed, so softeredged has the structure: $\left[_{\mathrm{Adj}}\left[{ }_{\mathrm{Nom}}\right.\right.$ softer edge] -ed]. ${ }^{19}$

What about adjectives of the small-scale type? These, we grant, are genuine adjectival compounds and can be inflected internally. Still - there always seems to be a still - this class of adjectival compounds is again relevantly different from darker(-)green and darkest(-)green in that its head, scale, distance, etc., is clearly a noun, i.e. a word that cannot carry a comparative or superlative inflection. We conclude that the only genuine adjectival compounds identified in the literature that can take internal comparative and superlative inflections are compounds whose heads are nouns. Note that this is perfectly compatible with the view that the CT in dark(-)green and its derivatives is (sometimes) a noun. 


\subsubsection{The oddity disappears if the first element is an adverb} adjectives modifying adjectives is not the only one. We saw that Meys argued that the first element in a dark(-)green compound is an adverb. As hinted in the literature review, the odds were against such a proposal: given the existence of brightly, darkly, lightly and palely (cf. McCawley's argument), the words bright, dark, light, or pale make for unconvincing adverbs. The examples elicited by queries (ii) and (iii) make that option even less palatable. Not only would bright, dark, light, or pale have to be adverbs, but adverbs that take typical adjectival inflections for the comparative and superlative forms. That solution, we conclude, is unattractive. (For more arguments against the Meys-type analysis, see Payne et al. [2010: 54f.]).

Now, if bright, dark, light, and pale are indeed adjectives, then it would be most natural to categorise the $\mathrm{CT}$ with which they combine as a noun. We have seen several explicit cases of predicative uses of CSs that must be nominal. Take example (4) again:

(4) [...] until the broccoli has turned a dark green with no hint of blue. (COCA)

It is not illegitimate to ask if the nominal analysis cannot apply to attributive instances too. After all, an NP like dark green broccoli, which contains an attributive CS, is paraphrasable by an NP that contains a predicative CS, as in broccoli that is dark green or in broccoli that is a dark green. The CS in the latter is unequivocally nominal. This shows that it is not unreasonable to leave the door open to the possibility that nominal CTs may occur in attributive CSs too. Of course, this raises the question whether, outside of the 'other' function, there can be nominal occurrences of CTs that bear no marks of their nounhood - they are not plural; they are not the head of a phrase whose first word is a determiner. We return to this issue in Section 4.

\subsubsection{McCawley's dual-membership proposal}

In Section 1, we also briefly alluded to McCawley's proposal, only to say that it was summarily dismissed by Aarts [2007:133-34]. Now is the time to reconsider the proposal. McCawley gives the examples and the acceptability judgments below as bearing out that colour terms have dual category membership. Their reduced acceptability (or downright unacceptability), McCawley suggests, results from the fact that the comparative/superlative form of deep explicitly requires that blue be a noun, even though, as a modifier of shirt, it must simultaneously be an adjective.

(33) ?John is wearing a deeper blue shirt than he usually does.

(34) ??John is wearing the deepest blue shirt that I've ever seen.

(35) *John is wearing a deep bluer shirt than he usually does.

McCawley identifies explicit inflectional marking as the culprit: "When inflections intrude [on deep] it [= the colour term] is forced to commit itself to only one of its categories and thereby makes one of the two configurations in which it occurs illformed" [1988: 745]. Thus, in both (33) and (34), the comparative and superlative inflections deeper and deepest show unambiguously that deep is an adjective, and blue can then only be a noun, which clashes with its function as a modifier of shirt. A similar reasoning applies to (35), where the comparative bluer this time excludes the 
interpretation of the colour word as a noun, an interpretation nevertheless demanded by the presence of the adjectival modifier deep.

That is why the examples (33)-(35) are scarcely or not at all acceptable, says McCawley, who further notes that comparative and superlative forms of the modifier of the CT are allowed provided they occur in constructions which solely exploit its noun properties. This is notably the case in predicative use:

(36) John's shirt is a deeper blue than Arthur's.

(37) John's shirt is the deepest blue that I've ever seen.

50 deep bluer would also be unacceptable in predicative position since, there too, bluer would exclude the nominal reading of blue demanded by modifier deep. We scoured the BNC and COCA for examples of the dark(-)greener type and came up empty-handed, which confirms the validity of that prediction. Still, McCawley's proposal is flawed. Whereas Aarts does not take issue with McCawley's acceptability judgments, we do. Occurrences with deeper or deepest modifying a $\mathrm{CT}$ in attributive position are admittedly infrequent in the BNC and COCA, but there are some all the same. Here are two examples:

(38) The early flowering Fuji cherry Prunus incisa February Pink opens its single shell-pink blossom almost as soon as the deeper pink flowers of the sweet almond Prunus dulcis. (BNC)

(39) A single brilliant and prolonged diamond ring was followed by the corona set in the darkest, deepest blue sky I had seen at any eclipse. (COCA)

What is more, the corpora contain quite a few examples with our set of four key modifiers.

(40) Caroline has lighter brown hair than her sisters [...]. (COCA)

(41) At first we didn't see that Jackfish was different from her other boyfriends except he had the brightest red hair I ever saw [...]. (COCA)

51 We conclude that McCawley's theory makes predictions that disqualify it: the challenge remains. We take it up in Section 4, after we have discussed the other key finding of our corpus study, that is, the discrepancy in the results for hyphenated and unhyphenated composite CSs.

\subsection{Unhyphenated vs. hyphenated composite CSs}

The analysis of the results in Section 2 has revealed interesting dissimilarities between unhyphenated and hyphenated composite CSs. Two points in particular stand out:

a. compared to their unhyphenated counterparts, hyphenated composite CSs seem averse to comparative or superlative forms, as is starkly revealed by a comparison of Tables 2 and 3;

b. compared to their unhyphenated counterparts, hyphenated composite CSs seldom occur overtly as nouns. That is demonstrated by the non-existence of plural occurrences (Table 3 again). It is also borne out by the small number of occurrences in the 'other' position (Table 5) and the rarity of occurrences with a determiner in the predicative function (Table 8).

The corpus does not tell us how to interpret these findings, but we can venture some tentative hypotheses. To begin with, point (a) is compatible with the notion that 
hyphenated composite CSs are quintessential compounds. They very much tend to function externally like single words (cf. Section 3.1.1.), since they are almost impenetrable to inflections. It is therefore tempting to venture that they are much more compound-like than their unhyphenated counterparts or, alternatively, that in the vast majority of cases they occur as compounds, whereas unhyphenated composite CSs are more versatile.

As for point (b), it invites the conclusion that hyphenated composite CSs are essentially adjectival. Once again, their unhyphenated counterparts appear more flexible, being definitely capable of occurring as nouns in a not insignificant number of instances.

Taken together, these observations suggest that hyphenated composite CSs are well and truly adjectival compounds. They conform to the picture of composite CSs that dominates in the literature. The only aspect of that picture that cannot be confirmed (or disconfirmed) on the basis of our corpus findings is the adjectival category of the first element.

By contrast, unhyphenated composite CSs fit less well into the straitjacket of the exemplary adjectival compound, since they are less averse to internal inflection and more likely to occur as overtly marked nouns. All of this suggests a rather nuanced answer to the question of the category membership of composite CSs. We outline such an answer in the next section.

\section{A nuanced picture}

We started out with an intuition that assigning CTs to a lexical category might be trickier than the apparent consensus in the literature hinted. That intuition has been largely supported by our corpus study. We must now consider its potential theoretical implications.

One of the main confirmations to emerge was that CTs can occur as nouns in composite CSs outside the 'other' function. Indeed, there are many occurrences of predicative composite CSs whose head is a noun, as in (42)-(44):

(42) His long neck was tinged a bright pink as though reflecting some internal glow. (BNC)

(43) Paint the centres a darker green. (BNC)

(44) [...] the young woman cocked a head to the jukebox, turned the brightest

red I have ever seen on the female flesh, and spun on the good father. (COCA)

The morphosyntactic analysis of these occurrences is straightforward. Because the head of the string is a noun, its modifier bright/dark/light/pale can only be an adjective, and that is just as it should be. There is no question of an adjective modifying an adjective here. Besides, it is unsurprising that the adjective in the string should carry marks for grade, as a noun is not normally regarded as gradable (cf. our discussion of small-scale in Section 3.1.1.). Hence, examples like (43) and (44) are unremarkable.

Once that is established, it is legitimate to ask if such a straightforward analysis cannot be carried over to occurrences with no overt nominal marking. Let us start with the predicative position: why not say that the composite CSs in examples (45) and (46) are headed by a colour noun too?

(45) The leaves are pale green, fleshy, almost round with a wavy edge [...] (BNC) 
(46) The Virgin's robe is darkest blue, [...] (COCA)

We can initially think of three possible objections: (i) the composite CS occurs without a determiner; (ii) there can be modification by adverbs compatible only with adjectival heads; (iii) we saw that there was a strong case for saying that hyphenated composite CSs were adjectival compounds: should not we therefore propose the same analysis for their unhyphenated counterparts (whenever that is possible)?

Let us first dispose of (iii): though we understand the attraction of a common account, our attitude in this paper is to remain open to surprising findings. Hence, we are not at the start committed to the view that unhyphenated and hyphenated composite CSs must receive an identical explanation. Actually, the results of our corpus study rather hint that they should not.

Turning now to (i), the absence of a determiner is not in itself an argument against a nominal CT. Dictionaries record colour nouns as being either count or noncount. As Payne et al. write, "[t]he omission of the article would be comparable in that case to the omission of the article with predicative nouns of material composition, as in This shirt is cotton" [2010:54]. ${ }^{20}$ One example of a composite CS in the 'other' function we gave previously, (28), has a noncount occurrence of the CT.

(28) [...] the compounds are really quite beautiful, occurring in shades of bright-red, yellow, and brown. (COCA) (repeated)

Concerning objection (ii), it is definitely true that examples like (47) and (48) do crop up:

(47) My friends and I lost each other, and the stage was so bright red and they totally held it with just the two of them. (COCA)

(48) [...] beat egg yolks and remaining cup sugar 5 minutes or until thick and very pale yellow. (COCA)

In (47), so forces bright red to be an adjectival string, headed by the adjective red. If red were a noun and so modified only bright, we would have so bright a red. (48) is different, however. As far as we can tell, there are two possible analyses of very pale yellow, as shown in (49):

(49) a. very [pale yellow] b. [very pale] yellow

According to the first analysis, which is perhaps the less likely, pale yellow can only be adjectival. On the second, however, only pale is modified by very, and yellow could still be a noncount noun. We can see, therefore, that even when there are no markers of nounhood, the nominal analysis remains viable in at least some cases. Note in passing that our analysis of (48) also implies that not all strings made up of bright/dark/light/ pale and a CT form a constituent. So maybe our initial cautious choice of the label string was misleading after all.

The availability of more than one analysis for some composite CSs can be demonstrated even more strikingly if one looks at complex attributive cases as in (50), an example which can be parsed in at least four ways, as shown in Table 9:

(50) "Pilar," she whispered and winked at me with very dark brown eyes. (COCA) 
Table 9: Four syntactic analyses of example (50)

\begin{tabular}{|l|l|l|}
\hline & & gloss \\
\hline a) & {$\left[_{\mathrm{NP}}\left[_{\mathrm{AP}}\right.\right.$ very $\left[_{\mathrm{Adj}}\right.$ dark brown $\left.]\right]$ eyes $]$} & 'eyes that are dark brown to a high degree' \\
\hline b) & {$\left[_{\mathrm{NP}}\left[_{\mathrm{AP}}\right.\right.$ very dark $]\left[_{\mathrm{Nom}}\left[_{\mathrm{AP} ?}\right.\right.$ brown $]$ eyes $\left.]\right]$} & 'brown eyes that are very dark' \\
\hline c) & {$\left[_{\mathrm{NP}}\left[_{\mathrm{AP}}\right.\right.$ very dark $]\left[_{\mathrm{AP}}\right.$ brown $]$ eyes $]$} & 'eyes that are both very dark and brown' \\
\hline d) & {$\left[_{\mathrm{NP}}\left[_{\mathrm{AP} / \mathrm{Nom}}\left[_{\mathrm{AdvP} / \mathrm{AP}}\right.\right.\right.$ very dark $]$ brown $]$ eyes $]$} & 'eyes that are (a) very dark brown' \\
\hline
\end{tabular}

We do not claim that all these analyses are equally likely. For instance, c) would be more readily available if a comma separated dark and brown. Still, they are all at least possible. Besides, they say different things about the category of brown. In a), it must be adjectival. In b) and c), it most likely is too (though the noncount noun cannot be completely ruled out, which is why we have added a question mark after subscript $A P$ ). In d), it could be argued to be either an adjective or a noun. However, if brown is adjectival, then two analyses are available for very dark. Either it is an AP modifying an adjective, an unattractive proposal, especially because we are not in a compound environment where exceptional rules might apply (cf. Marchand in Section 1) - dark brown does not even form a constituent in d). Or we must take very dark to be adverbial - in line with Meys's proposal - which we have also shown not to be an attractive solution. In other words, the analysis in which brown is a noun definitely has the edge in d). This confirms what we suggested in Section 3.1.2., namely that it was legitimate to consider extending the nominal analysis to at least some attributive instances.

The overall lesson is that blanket generalisations are ill-advised. So is excessive reliance on analogies and insertion tests. The fact that colour words can occur both attributively and predicatively does not mean that they are adjectives. Noncount nouns too can occur in both positions. The mere fact that composite CSs can be modified by very or so does not automatically mean they are all adjectival. If such an insertion test was said to be decisive, then one should say the same about a different insertion test, namely the addition of a determiner before the composite CS. If the fact that one can say the stage was so bright red next to the stage was bright red proves that red is adjectival, then, by the same token, the fact that one can say the stage was a bright red next to the stage was bright red proves that red is nominal. Since, however, these conclusions are inconsistent with each other, we have to conclude that insertion tests are not decisive.

What emerges from the previous discussion is that there is no one-size-fits-all response to our initial question about the category membership of CTs. Two categories are open to them. Sometimes identifying the category is easy because only one syntactic analysis is possible (cf. examples (42)-(44) and (47)). At other times, nothing seems to constrain syntactic analysis enough that only one reading is tenable. In those cases - (45), (46), (48) - one must be able to accept that there are competing accounts, each more or less attractive. It may be too that further research, relying on factors we may have neglected in the present study, will succeed in refining our ability to discriminate between adjectival and nominal occurrences. 


\section{Conclusion}

\section{(1)} about category membership can bring rewards. In this paper, we were not asking if colour terms as a group are either adjectives or nouns: we were looking at uses of colour terms. With the support of a corpus study, we were able to confirm our initial intuition that dominant accounts, which pit adjectival attributive and predicative uses against nominal 'other' uses, are simplistic. First, there is a large set of predicative uses that are indisputably nominal. Second, a good many of the remaining predicative uses are compatible with both an adjectival and a nominal analysis. In many of these cases, the nominal analysis might be said to have the edge, because it obviates two major difficulties faced by the adjectival analysis: how can an adjective modify an adjective? And, if one takes the structure to be a compound, what is one to make of comparative and superlative inflections that are added internally to the modifier instead of the head of the structure?

Still, it was not our purpose to extend the nominal analysis beyond reasonableness. In the end, the only option is to accept that, in between those cases that are clear-cut because morphosyntax excludes all but one analysis, there is a fuzzier middle ground. Whether that middle ground is eventually compatible with a framework that maintains strict separation between categories (like Huddleston \& Pullum's) or calls for a conception of grammatical phenomena and categories as gradient (like Aarts's) is a question we leave for further research.

\section{BIBLIOGRAPHY}

AARTS Bas, 2007, Syntactic Gradience: The Nature of Grammatical Indeterminacy, Oxford: OUP.

ADAMS Valerie, 1973, An Introduction to Modern English Word-Formation, London: Longman.

ADAMS Valerie, 2001, Complex Words in English, Abingdon: Routledge.

ANDERSON Stephen, 1992, A-Morphous Morphology, Cambridge: CUP.

ATTAL Jean-Pierre, 1987, Grammaire et usage de l'anglais, Paris: Duculot.

BAUER Laurie, 1983, English Word-Formation, Cambridge: C.U.P.

BAUER Laurie, 2006, “Compound”, in BROWN Keith (Ed.), Encyclopedia of Language and Linguistics ( $2^{\text {nd }}$

ed.), vol. 2, Oxford: Elsevier, 719-726.

Lexis, 15 | 2020 
BAUER Laurie \& HUDDLESTON Rodney, 2002, “Lexical word-formation”, in HUDDLESTON Rodney \& PULLUM Geoffrey (Eds.), 2002, 1621-1721.

BERLIN Brent \& KAY Paul, 1969, Basic Color Terms: Their Universality and Evolution, Berkeley \& Los Angeles: University of California Press.

BLEVINS James P., 2006, “English inflection and derivation”, in AARTS Bas \& MCMAHON April (Eds.), The Handbook of English Linguistics, Oxford: Blackwell, 507-536.

CARSTAIRS-MCCARTHY Andrew, 2002, An Introduction to English Morphology: Words and Their Structure, Edinburgh: Edinburgh University Press.

CHUQUET Hélène \& PAILLARD Michel, 2007, "Les adjectifs composés en X + V + - ing: prédication, collocations, traductions", Palimpsestes [Online version], 19.

CONTI Sara, 2007, Compound Adjectives in English: A descriptive approach to their morphology and functions, Unpublished $\mathrm{PhD}$ dissertation, Università di Pisa.

DAVIES Mark, 2004-, British National Corpus (from Oxford University Press), available online at https://www.english-corpora.org/bnc/

DAVIES Mark, 2008-, The Corpus of Contemporary American English (COCA): 560 million words, 1990-present, available online at https://www.english-corpora.org/coca/

HASPELMATH Martin, 2007, “Pre-established categories don't exist: Consequences for language description and typology", Linguistic Typology, 11, 119-132.

HASPELMATH Martin \& SIMS Andrea D., 2010, Understanding Morphology, London: Hodder Education. HUDDLESTON Rodney \& PULLUM Geoffrey, 2002, The Cambridge Grammar of the English Language, Cambridge: CUP.

JESPERSEN Otto, 1942, A Modern English Grammar on Historical Principles, vol. 6, London: Allen \& Unwin.

KAY Paul \& MCDANIEL Chad K., 1978, “The Linguistic Significance of the Meaning of Basic Color Terms", Language 54, 610-646.

KRUISINGA Etsko, 1932, A Handbook of Present-Day English, Part II, English accidence and syntax, 3 volumes, $5^{\text {th }}$ edition, Groningen: Noordhoff.

LIEBER Rochelle, 2009, “IE, Germanic: English”, in LIEBER Rochelle \& ŠTEKAUER Pavol (Eds.), The oxford Handbook of Compounding, Oxford: OUP, 357-369.

MARCHAND Hans, 1966, The Categories and Types of Present-Day English Word-Formation, Tuscaloosa: University of Alabama Press.

MCCAWLEY James D., 1988, The Syntactic Phenomena of English, vol. 2, Chicago: The University of Chicago Press.

MEYS Willem Johannes, 1975, Compound Adjectives in English and the Ideal Speaker-Listener: A study of compounding in a transformational-generative framework, Amsterdam: North Holland Publishers.

PAYNE John, HUDDLESTON Rodney \& PULLUM Geoffrey, 2010, “The distribution and category status of adjectives and adverbs", Word Structure, 3, 31-81.

PLAG Ingo, 2003, Word-Formation in English, Cambridge: CUP.

POUTSMA Hendrik, 1914, A Grammar of Late Modern English: for the use of continental, especially Dutch, students. Part II: The Parts of Speech, Section 1, A: Nouns, adjectives and articles, Groningen: Noordhoff. 
PULLUM Geoffrey \& HUDDLESTON Rodney, 2002, “Adjectives and adverbs”, in HUDDLESTON Rodney \& PULLUM Geoffrey (Eds.), The Cambridge Grammar of the English Language, Cambridge: CUP, 525-595.

QUIRK Randolph, GREENBAUM Sidney, LEECH Geoffrey \& SVARTVIK Jan, 1985, A Comprehensive Grammar of the English Language, London: Longman.

SCALISE Sergio \& BISETTO Antonietta, 2009, "The Classification of Compounds", in LIEBER Rochelle \& ŠTEKAUER Pavol (Eds.), The Oxford Handbook of Compounding, Oxford: OUP, 34-53.

\section{Dictionaries}

Concise Oxford Dictionary of Current English, $1981^{6}$ (1911), Oxford, Clarendon Press.

Le Robert \& Collins. Dictionnaire Français-Anglais Anglais-Français, $1993^{3}$ (1978), Londres, Collins /

Paris, Le Robert.

Macmillan English Dictionary for Advanced Learners, 2002, Oxford, Macmillan Education.

Oxford Advanced Learner's Dictionary, $2005^{7}$ (1948), Oxford, Oxford University Press.

Oxford Dictionary of English (electronic dictionary).

Oxford English Dictionary, 1989², 20 vol., Oxford, Clarendon Press.

WEBSTER Noah, 1995, A Dictionary of the English Language, revised by GOODRICH Chauncey, London, Routledge and Sons Ltd.

www.oxfordlearnersdictionaries.com (online)

\section{NOTES}

1. We picked up eight dictionaries we had at hand (see references) and found the distinction made in all of them.

2. Unless otherwise mentioned, all examples are from the following corpora: BNC: British National Corpus (Davies [2004-]) and COCA: The Corpus of Contemporary American English (Davies [2008-]). These were accessed mainly in 2011 and 2012 via the interface created by Mark Davies. More information about corpus data is provided in Section 2.

3. For clarity, 'other' stands for the following four functions: (head of) subject NP, (head of) complement NP of a preposition, head of an NP that includes a PP-complement of the CT, head of an NP with a plural inflection.

4. We use the noun 'nominal' as defined in Huddleston \& Pullum [2002: 329]. A nominal is roughly equivalent to an $\mathrm{N}$ ' ('N bar') in generative syntax. Our terminology aligns with Huddleston \& Pullum [2002] as much as possible.

5. We use the neutral term string to avoid labels that suggest that we are dealing either with syntactic groups (e.g. phrases) or with lexical units (e.g. terms). We often abbreviate composite colour string to composite $C S$.

6. When convenient, we use dark(-)green as short for all composite CSs, hyphenated or not. We will have nothing to say about combinations written solid. In neither the BNC nor the COCA did we come across a single such occurrence.

7. Other linguists who, without mentioning composite CSs, admit adjective-adjective adjectival compounds are Carstairs-McCarthy [2002: 61] and Scalise \& Bisetto [2009: 39].

8. Our reason for singling out these four modifiers is given in Section 2.1.

9. Meys is here referring to the first $\mathrm{CT}$ in compounds like red-brown or bluish-green. 
10. These are McCawley's grammaticality judgments. The COCA contains several examples of deeply blue, etc. with the CT used literally. It also has many instances of lightly brown but very few with other CTs.

11. We return to McCawley's proposal in Section 3.1.3.

12. Like Huddleston \& Pullum [2002], we use plain as a synonym of uninflected. The term allows us to group together occurrences that may be either adjectival or nominal. Plural occurrences, obviously, can only be nominal.

13. There are two composite CSs in this example. Only the one that was returned as a hit by the interface is underlined. The same remark applies to example (24) below.

14. 2 corpora $\mathrm{x} 3$ forms of compositeness $\mathrm{x} 2$ numbers $\mathrm{x} 12$ CTs.

15. For clarity, there are no columns for the raw data. Regarding query (i), 252 hits were spurious (1.56\%). 13 hits (3.75\%) proved spurious for query (ii), and 9 (7.56\%) for query (iii).

16. Some (implicit) reasons for lumping these two minor functions together with the predicative function can be found in Quirk et al. [1985: 418-419] and Huddleston \& Pullum [2002: 529].

17. Several informal tallies we performed with simplex CTs appear to find the attributive use to prevail as well.

18. We are using the hyphenated spellings simply because they are more usual than Anderson's.

19. Subscript Nom is short for Huddleston \& Pullum's nominal.

20. For the record, Payne et al. go on to argue against colour nouns heading composite CSs in cases like (45)-(46).

\section{ABSTRACTS}

This paper looks into the category membership of colour words that enter into combination with modifiers like bright, dark, light, or pale. The English grammatical literature usually assumes that these 'composite colour strings', used attributively or predicatively, form adjective-adjective compounds. Closer scrutiny, however, reveals difficulties with this view. First, it is unusual for adjectives to modify adjectives. Second, even if they are compounds, it is unusual for their comparative and superlative inflections to be marked not on the head of the structure, but internally on the modifier, as in brighter red. These difficulties lead us to question the compoundhood of those strings, but also to explore the possibility that, at least in some predicative and attributive uses, the colour words in them are nouns. Using data from the BNC and COCA, we test our intuitions and those found in the literature. We conclude that the adjective-adjective compound analysis of composite colour strings cannot be generalised to all predicative and attributive uses. In at least some of those, the colour word is a noun. In some other cases, it may not be possible to decide if the colour word is a noun or an adjective.

Cet article est consacré à la catégorisation grammaticale des termes de couleur lorsqu'ils sont précédés de modifieurs tels que bright, dark, light ou pale, dans des structures nommées en anglais " composite colour strings ». Il est souvent admis dans la littérature que ces séquences, qu'elles soient épithètes ou attributs, forment des composés adjectif-adjectif. Une étude plus approfondie révèle toutefois les écueils d'une telle analyse. Premièrement, il est inhabituel qu'un adjectif modifie un autre adjectif. Deuxièmement, même s'il s'agit de composés, il est inhabituel que les marques du comparatif et du superlatif soient portées non par la tête de la structure mais, de façon interne, par le modifieur (comme dans brighter red). Ces obstacles nous ont conduits à une 
remise en question du statut de « composés » de ces séquences; ils nous ont également amenés à nous demander si, au moins dans certains emplois épithètes et attributs, les termes de couleur ainsi utilisés n'étaient pas des noms. Nous appuyant sur les données du BNC et du COCA, nous avons vérifié nos intuitions et celles trouvées dans la littérature et sommes arrivés à la conclusion que l'analyse des composite colour strings en tant que composés adjectif-adjectif ne peut être généralisée à tous leurs emplois épithètes et attributs. Dans certains cas, le terme de couleur est un substantif. Dans d'autres, il pourrait être impossible de déterminer si le terme de couleur est un nom ou un adjectif.

\section{INDEX}

Keywords: colour terms, lexical category, adjectival compound, predicative use, attributive use Mots-clés: termes de couleurs, catégorie lexicale, composé adjectival, emploi attribut, emploi épithète

\section{AUTHORS}

\section{PHILIPPE DE BRABANTER}

Université Libre de Bruxelles

pdebraba@ulb.ac.be

\section{SAGHIE SHARIFZADEH}

Sorbonne université

saghie.sharifzadeh@sorbonne-universite.fr 